\title{
Applications of Meteorological Tower Data at Kennedy Space Center
}

\author{
Karen M. Altino ${ }^{1}$ \\ NASA /Marshall Space Flight Center, Huntsville, AL, 35812 \\ and \\ Robert E. Barbré, Jr. ${ }^{2}$ \\ Jacobs Engineering, ESTS Group, Huntsville, AL, 35806
}

Members of the National Aeronautics and Space Administration (NASA) design and operation communities rely on meteorological information collected at Kennedy Space Center (KSC), located near Cape Canaveral, Florida, to correctly apply the ambient environment to various tasks. The Natural Environments Branch / EV44, located at Marshall Space Flight Center in Huntsville, Alabama, is responsible for providing its NASA customers with meteorological data using various climatological data sources including balloons, surface stations, aircraft, hindcast models, and meteorological towers. Of the many data sources available within the KSC region, meteorological towers are preferred for near-surface applications because they record data at regular, frequent intervals over an extensive period of record (POR) at a single location. This paper discusses the uses of data measured at Launch Complex 39B (Pad 39B) and Tower 313 for the 1995-2007 POR, and how the data is being applied to various engineering decisions for the new Constellation Program Ares and Orion space vehicles.

Performing comparisons between multiple data sources shows the sensitivity of using meteorological data from a particular source to answer a given engineering question. Comparisons between meteorological variables from Tower 313 and the 10 meter tower at the Shuttle Landing Facility show the consequences of using data from different sources for a given engineering application. Concurrent mean and peak wind speeds, temperature, and dew point from both data sources at similar measurement altitudes were compared. The differences between these variables from the different data sources show that the instrument locations and measurement heights can have a significant impact on the environmental inputs of a given engineering analysis. The end result of the engineering analysis is thus also affected at a significance which depends on its sensitivity to the meteorological parameter.

In addition, sample results of statistical analyses using tower data are presented relating to the Orion capsule after a pad abort as well as situations when the Ares and Orion integrated stack is being transported to and remaining on the pad. Monthly landing availabilities from Tower 313 show how often an operation sensitive to given wind speed thresholds, such as an Orion landing after a pad abort, could be implemented. Generally, availabilities are better (worse) during the summer (winter) months, but individual availabilities vary depending on the month and wind speed threshold chosen. Wind speeds at given percentiles from Tower 313 are presented based on given months, altitudes, and wind directions, and show that the highest winds occur generally from a northerly direction during the autumn and winter months. Tropical systems can also influence the wind data at extreme percentiles. Temperature versus relative humidity scatter plots from Pad 39B can be constructed to assist in vehicle purge analyses, which are sensitive to various temperature and humidity combinations. The analyses provided are samples of data generated by EV44 to assist NASA with applications sensitive to various meteorological variables.

\footnotetext{
${ }^{1}$ Flight Vehicle Atmospheric Environments Engineer, Natural Environments Branch / EV44, Marshall Space Flight Center / EV44.

${ }^{2}$ Natural Environments Engineer, Natural Environments Branch / EV44, Marshall Space Flight Center.
} 


\title{
Applications of Meteorological Tower Data at Kennedy Space Center
}

\author{
Karen M. Altino ${ }^{1}$ \\ NASA/Marshall Space Flight Center, Huntsville, AL 35812 \\ and \\ Robert E. Barbré, Jr. ${ }^{2}$ \\ Jacobs Engineering ESTS Group, Huntsville, AL 35806
}

\begin{abstract}
Members of the National Aeronautics and Space Administration (NASA) design and operation communities rely on meteorological information collected at Kennedy Space Center (KSC), located near Cape Canaveral, Florida, to correctly apply the ambient environment to various tasks. The Natural Environments Branch/EV44, located at Marshall Space Flight Center (MSFC) in Huntsville, Alabama, is responsible for providing its NASA customers with meteorological data using various climatological data sources including balloons, surface stations, aircraft, hindcast models, and meteorological towers. Of the many resources available within the $\mathrm{KSC}$ region, meteorological towers are preferred for near-surface applications because they record data at regular, frequent intervals over an extensive period of record at a single location. This paper discusses the uses of data measured at several different meteorological towers for a common period of record and how the data can be applied to various engineering decisions for the new Constellation Program Ares and Orion space vehicles.
\end{abstract}

$\begin{array}{ll} & \\ C x P & =\text { Constellation Program } \\ D S N E & =\text { Design Specification for Natural Environments } \\ E \& C & =\text { Environments and Constraints } \\ K S C & =\text { Kennedy Space Center } \\ m & =\text { meter(s) } \\ m / s & =\text { meters per second } \\ M S F C & =\text { Marshall Space Flight Center } \\ N A S A & =\text { National Aeronautics and Space Administration } \\ N C D C & =\text { National Climatic Data Center } \\ N E D D & =\text { Natural Environment Definition for Design } \\ P O R & =\text { Period of Record } \\ Q C & =\text { Quality Control } \\ S I G & =\text { Systems Integration Group } \\ S L F & =\text { Shuttle Landing Facility }\end{array}$

${ }^{1}$ Flight Vehicle Atmospheric Environments, Natural Environments Branch/EV44, NASA/MSFC Mail Code EV44, Huntsville, AL 35812, Member.

${ }_{2}^{2}$ Natural Environments Engineer, Natural Environments Branch/EV44, P.O. Box 9030, Huntsville, AL 35812 , Member. 


\section{Introduction}

$\mathrm{N}$ ATURAL environments affect each and every mission phase of spaceflight. Terrestrial and space environments can affect pre-launch operations and hardware, launch and ascent operations, in-orbit space operations, and Earth landing and recovery operations. Environmental extremes are examined during the early stages of vehicle design to understand the limits a vehicle may be exposed to and allows engineers the opportunity to create a vehicle design that can best handle those extremes. The Natural Environments Branch/EV44 at National Aeronautics and Space Administration's (NASA's) Marshall Space Flight Center (MSFC) in Huntsville, Alabama, is responsible for providing environmental data to customers who work with spaceflight hardware. NASA's latest program, the Constellation Program (CxP), is one example of how environments are considered during the design stages of spaceflight vehicles. Many members of EV44 support the new Program and have helped develop environments documentation as part of CxP Level II Environments and Constraints Systems Integration Group (E\&C SIG). The E\&C SIG is responsible for the CxP Design Specification of Natural Environments ${ }^{1}$ (DSNE) and CxP Natural Environment Definition for Design ${ }^{2}$ (NEDD) documents which characterize the terrestrial and space environment specifications and detail how the environment extremes are derived.

As many key operations will take place at the Kennedy Space Center (KSC) in Florida, a variety of requests come into EV44 that relate to near-surface environments for the surrounding KSC area. A multitude of data sources exist at KSC. However, for near-surface environments, meteorological towers are the preferred data resource because the towers record data at regular, frequent intervals and data is continuously archived. Some of the towers most commonly used for analyzing KSC near-surface environments include the 10 meter $(\mathrm{m})$ tower at the Shuttle Landing Facility (SLF), the $18.3 \mathrm{~m}$ tower at Launch Complex 39B (hereafter referred to as Pad 39B), and Tower 313 (located between the two). As can be seen in Fig. 1, the SLF tower is approximately 4.0 miles inland while the tower at Pad 39B is located only a half mile inland. Tower 313 is located approximately 2.1 miles west of Pad 39B and, unlike the other two towers, it takes meteorological measurements at several different heights up to $150 \mathrm{~m}$.

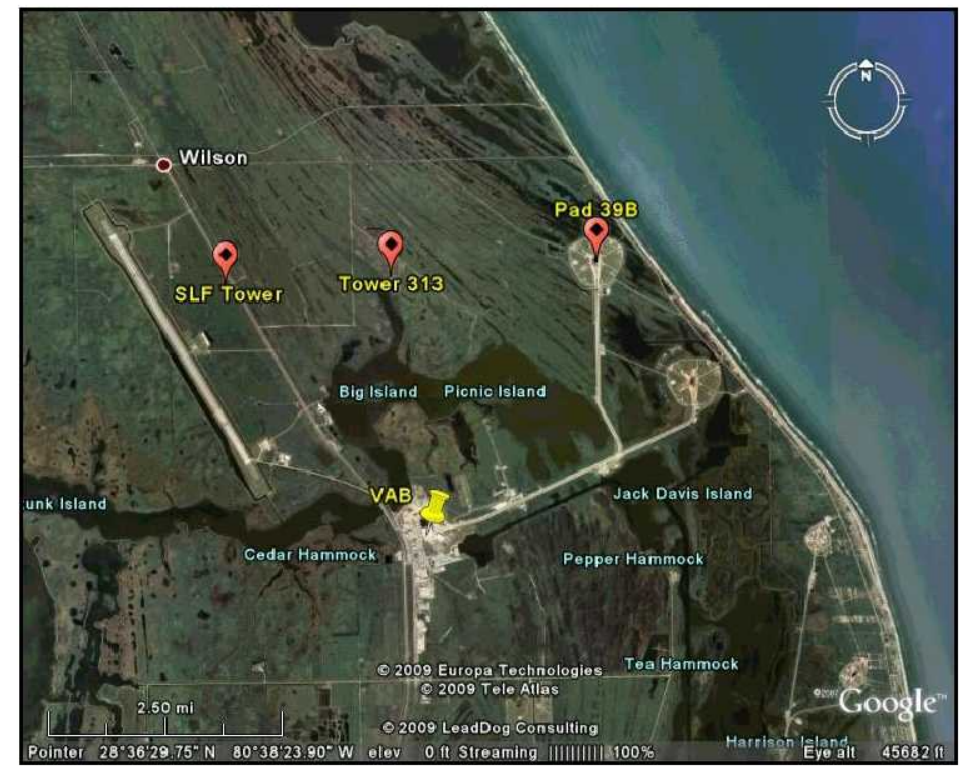

Figure 1. Google Earth map showing the locations of the three KSC towers that will be discussed in this paper. Tower 313 is located inland from the launch pads but not quite as far inland as the SLF tower. Tower 313 also has the ability to take meteorological measurements at multiple heights.

\section{Databases}

The three towers all collect and store data in various ways. The SLF, which records data at $10 \mathrm{~m}$, has data from 1978 - the year SLF was created for the Space Shuttle Program - and goes through present day. Observations are recorded every hour, and sometimes additional observations are recorded if there is a significant weather event occurring. Many meteorological variables are recorded, such as temperature, dewpoint, wind speed, and wind

2

American Institute of Aeronautics and Astronautics 
direction. The database also contains some information regarding precipitation and whether or not thunderstorms were observed in the area. For most variables, the hourly recorded value is the mean value of the last five minutes of the previous hour. Peak wind speed values are recorded as the highest 1-second guest over the 5-minute period. The data is quality controlled (QC'd) and archived through the National Climatic Data Center (NCDC)/Air Force Combat Climatology Center (AFCCC), located in Asheville, North Carolina.

The Pad 39B database contains data records for the 1995-2007 period of record (POR) at a height of $18.3 \mathrm{~m}$ on two individual towers located near the pad. Each 5-minute record contains 5-minute averages of temperature, dewpoint, relative humidity, wind direction, and wind speed, including the maximum 1-second, or "peak", wind speed during the reporting period. Temperature and dewpoint are reported to the nearest $0.1{ }^{\circ} \mathrm{C}$, and relative humidity is reported to the nearest whole percent. Temperature and relative humidity are directly measured by sensors on the tower, and the dewpoint is calculated in the data post-processing. Wind speed is measured in integer knots, but was converted to meters per second $(\mathrm{m} / \mathrm{s})$. For various reasons, the archived data contained erroneous data records. Therefore, before the data could be used, the erroneous records needed to be removed by applying an extensive QC process to the data ${ }^{3}$. This QC process generated a single database from the two towers by selecting data from the "upwind" tower.

Similar to Pad 39B, the Tower 313 database contains 5-minute reports of wind speed, wind direction, temperature, dewpoint, and relative humidity from two sensors - one on the northeast side and one on the southwest side - at eight heights for the 1995-2007 $\mathrm{POR}^{4}$. Meteorological measurements are taken at approximate heights of 2 $\mathrm{m}, 4 \mathrm{~m}, 16 \mathrm{~m}, 49 \mathrm{~m}, 62 \mathrm{~m}, 90 \mathrm{~m}, 120 \mathrm{~m}$, and $150 \mathrm{~m}$. Wind speed and wind direction are measured at all heights except at $2 \mathrm{~m}$; temperature, dewpoint, and relative humidity are only measured at four heights $-2 \mathrm{~m}, 16 \mathrm{~m}, 62 \mathrm{~m}$, and $150 \mathrm{~m}$. Characteristics of each variable are analogous to the Pad 39 database. Also, as with the Pad 39B database, the data as received by EV44 contained erroneous data records and those records needed to be removed by applying an extensive QC process to the data, creating a single database utilizing the "upwind" sensor.

\section{Applications and Data Comparisons Between Meteorological Towers}

Performing comparisons between multiple data sources shows the sensitivity of using meteorological data from a particular source to answer a given engineering question. Comparisons between meteorological variables from the different towers show the consequences of using different sources for a given engineering concern. Various concurrent observations from these data sources were compared. The differences between the variables from the different data sources show that the instrument locations and measurement heights can have a significant impact on the analysis results, and sensitivity to a certain meteorological parameter can impact the overall engineering analysis.

\section{A. Wind Speed Comparison Between Tower 313 and SLF}

One example of how the application of meteorological tower data to a particular engineering analysis can have varying affects can be seen in analyzing winds for Orion - the CxP crew exploration vehicle - in the case of pad aborts. Generally, availabilities are better (worse) during the summer (winter) months, but individual availabilities vary depending on the month and wind speed threshold chosen. Here, "availability" is analogous to the probability of the wind speed being below a given threshold; applications using availabilities rely on the wind being below the given threshold, so the probability of the wind being below the threshold is interpreted as the probability of the wind not inhibiting the application of interest.

A comparison was performed between SLF and Tower 313 availabilities based on wind speed from the SLF and Tower 313 databases for a $90 \mathrm{~m}$ height of interest ${ }^{5}$. Monthly availabilities were calculated by tallying the number of observations where the peak wind speed was below the given threshold for a given month throughout the POR, dividing by the number of valid observations within that month, then multiplying the result by $100 \%$. This process was implemented on peak wind speeds using both databases during the 1995-2007 overlapping POR.

First, availabilities were calculated on the hourly $10 \mathrm{~m}$ winds at SLF. Next, the wind thresholds were extrapolated from $10 \mathrm{~m}$ to $89.9 \mathrm{~m}$ using a peak wind profile model, which envelopes peak wind profiles to a specified risk level. A detailed description of the model can be found in the NEDD, but a short description is provided below.

The peak wind profile model is used to envelope the peak wind profile for peak wind speeds greater than $2.0 \mathrm{~m} / \mathrm{s}$ at the reference height, and is expressed by 


$$
u_{z}=u_{18.3}\left(\frac{z}{18.3}\right)^{k}
$$

where $u_{z}$ is the peak wind speed $(\mathrm{m} / \mathrm{s})$, at height $z(\mathrm{~m}), u_{18.3}$ is the peak wind speed $(\mathrm{m} / \mathrm{s})$ at the reference height of $18.3 \mathrm{~m}$, and $k$ is an exponent defined by

$$
k=c\left(u_{18.3}\right)^{-3 / 4} \text {. }
$$

In equation (2), $c$ is a normally-distributed variable defined by

$$
c=0.52+0.36 n,
$$

where $n$ is an input to the number of standard deviations from the mean $c=0.52(\mathrm{~m} / \mathrm{s})^{3 / 4}$. Here, selecting a value for $n$ envelopes the peak wind profiles to a specified risk level. Following equations (1), (2), and (3), selecting higher values of $n$ will yield more severe peak wind profiles for a given $u_{18.3}$ and, thus, higher thresholds at the height of interest. For this study, given wind thresholds were extrapolated from $10 \mathrm{~m}$ to $18.3 \mathrm{~m}$ before applying equations (1) $-(3)$.

Using the wind thresholds extrapolated to $89.9 \mathrm{~m}$ for different standard deviation inputs, availabilities were calculated from the Tower 313 database at $89.9 \mathrm{~m}$ - the closest reference height to the $90 \mathrm{~m}$ height of interest - at the top of each hour. Peak winds at the top of the hour were analyzed to be consistent with the SLF database, which only contains measurements at the top of the hour. Finally, the tower availabilities were subtracted from the SLF availabilities to yield a difference table. Tables 1(a), 1(b), and l(c) were generated for different $n$ inputs to see the effects of utilizing an enveloping profile model on availability for different wind speed thresholds and months.

Table 1. The difference in availabilities as a function of month and wind speed from Tower 313 and SLF for sigma levels (a) $n=0$, (b) $n=1$, and (c) $n=2$. Gray indicates difference in availabilities $\leq 0.1 \%$. Green indicates greater availabilities for SLF between 0.2 and $9.9 \%$. Orange indicates greater availabilities for Tower 313 between 0.2 and $9.9 \%$. Red indicates a difference $\geq 10 \%$ between the two.

a)

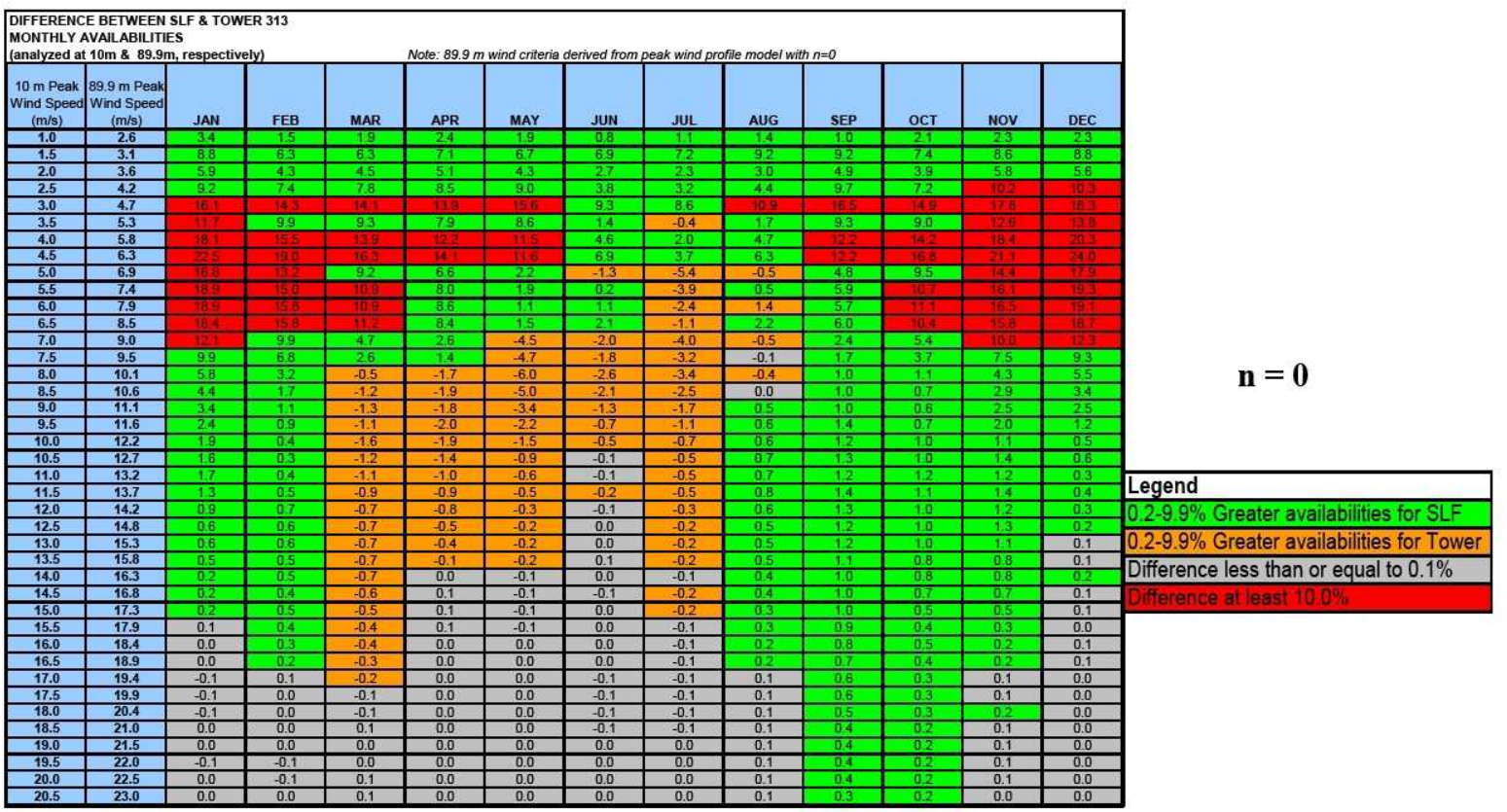


b)

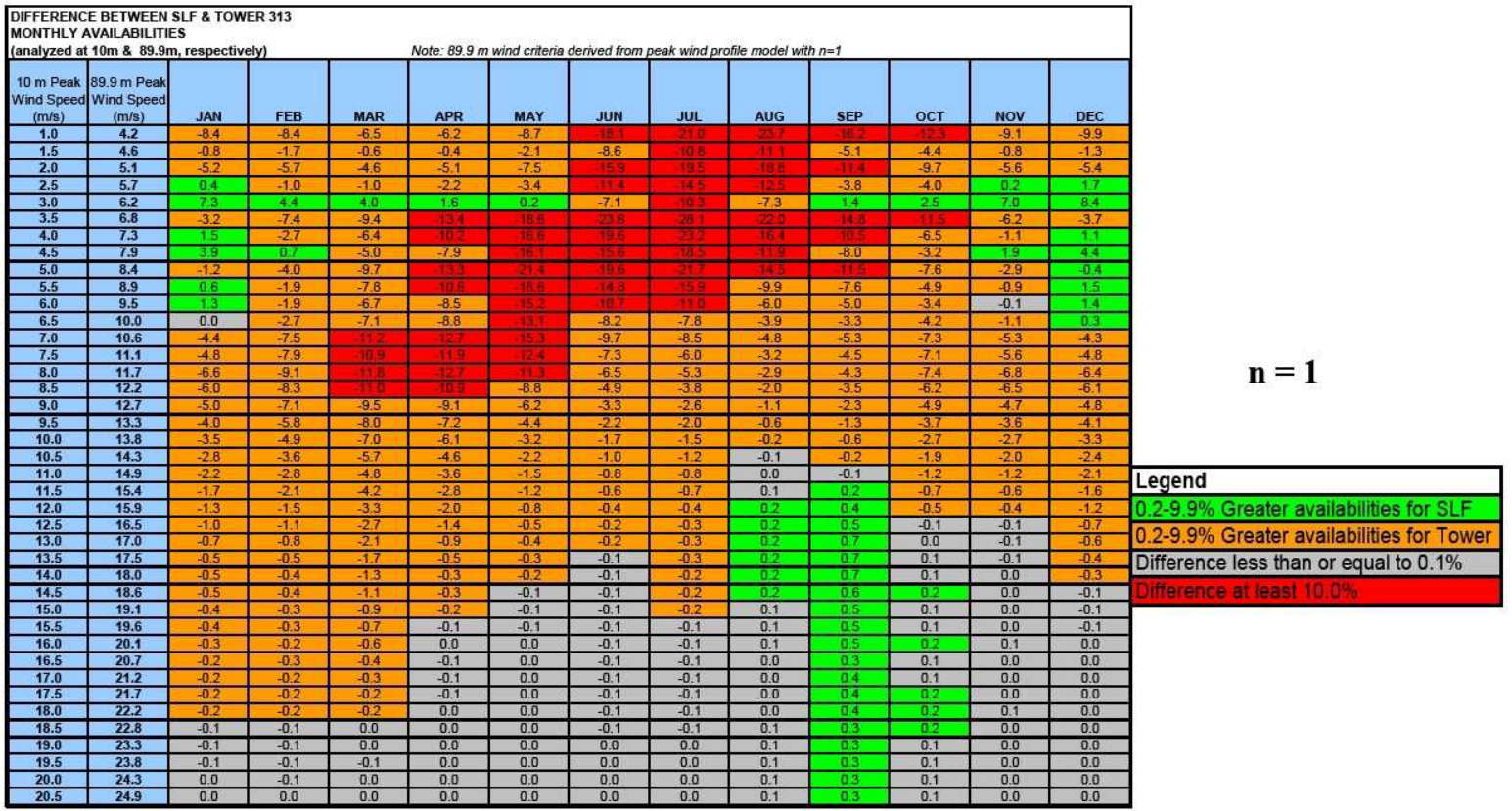

c)

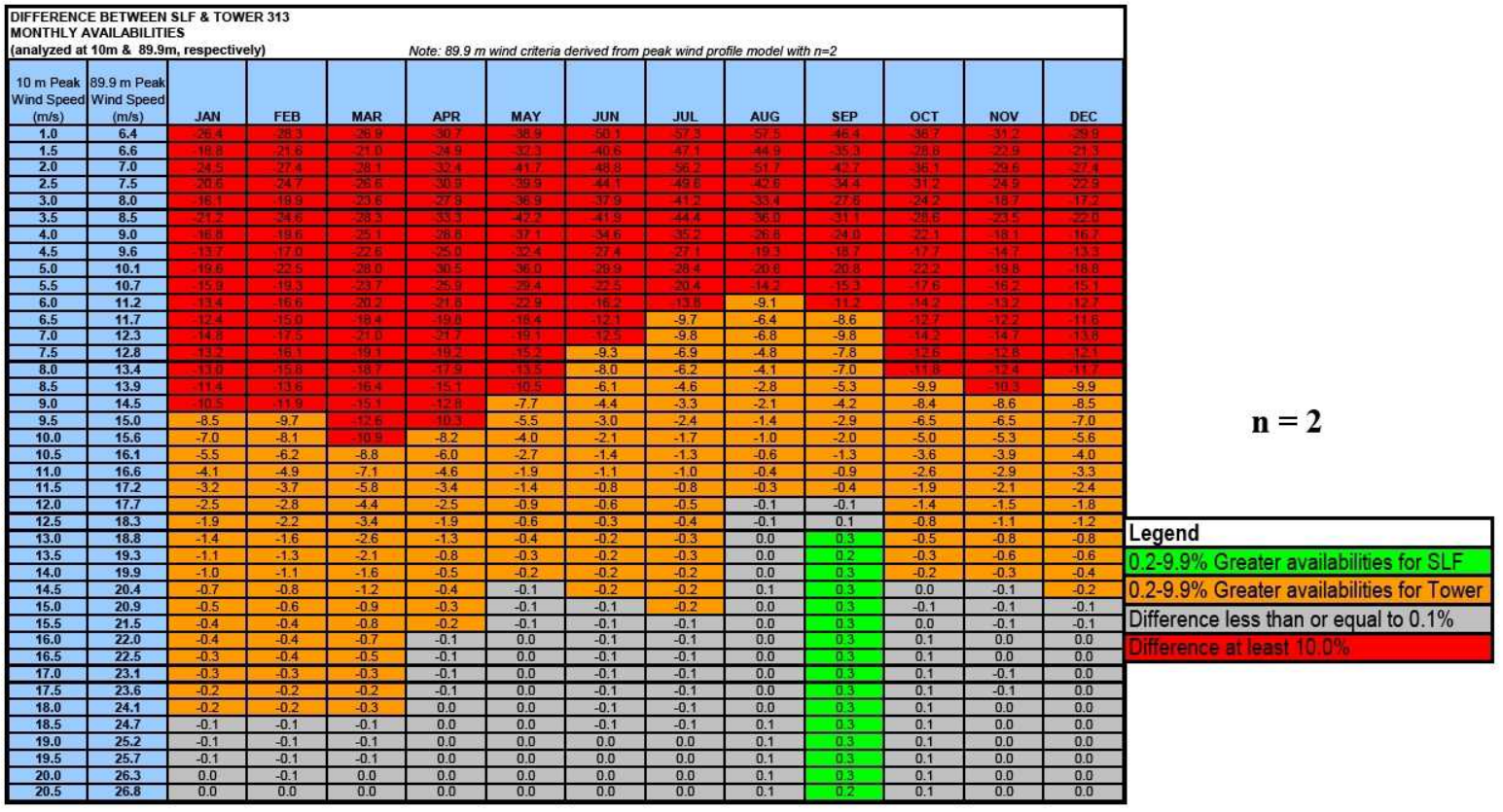

Table 1 reveals some significant differences in the availabilities calculated from the Tower 313 and SLF. The most significant differences were found at wind speed thresholds from $\sim 2 \mathrm{~m} / \mathrm{s}$ to $\sim 10 \mathrm{~m} / \mathrm{s}$. Table 1(a) shows the comparison for the standard deviation input $n=0$ case, or the "mean" profile. Here, the SLF has greater availabilities than Tower 313 from September-February for most of the wind speed thresholds. For thresholds below $10.0 \mathrm{~m} / \mathrm{s}$, differences above $10 \%$ - in favor of SLF - exist from August-May. Tower 313 does have greater availabilities from March-August at moderate to high wind speed thresholds, depending on the month. At higher thresholds the differences are, or are very close to, $0 \%$. This feature can be attributed to the availability being very close to $100 \%$ from each database. The difference in availabilities between these two databases show that using a profile model may or may not be sufficient in engineering analyses and that using data at the height of interest is optimal. 
To test the idea that the availability differences come from extrapolation of the peak wind and not differences in the data itself, Tables 1(b) and 1(c) were generated for different values of $n$ and show the differences in availabilities for $n=1$ and $n=2$, respectively. Here, the wind speeds at a specified height corresponding to a given wind speed threshold at $10 \mathrm{~m}$ increase as $n$ increases. In addition, note that the SLF availability calculations remain identical, so any change in the comparison is only due to the change in the Tower 313 availability calculations. The information in Table 1 shows that the availability differences between the two databases never seem to optimize at a specific $n$. The comparison for the $n=0.5$ case (not shown) shows the least differences outside of $+/-10 \%$. For the $n=1$ case, the availability differences have essentially reversed in sign from the $n=0$ case. Here, greater availabilities exist for the Tower 313 database for the majority of thresholds and months, and a significant number of differences over $10 \%$ (now in favor of Tower 313) exist from March-September. For the $n=2$ case, the Tower 313 database contains greater availabilities than SLF for nearly all months and thresholds, and differences over $10 \%$ exist for nearly all $10 \mathrm{~m}$ wind speed thresholds below $10.0 \mathrm{~m} / \mathrm{s}$. This case shows that the peak winds at $90 \mathrm{~m}$ are severely overestimated using SLF data and the peak wind model with $n=2$ as an input. Iterations were also done for other values of $n$ (e.g., $n=1.5$ ), but no $n$ was found that optimized the comparison enough to validate using an enveloping wind profile model to calculate availabilities in place of data which is available at the height of interest. These tests show that the input to the peak wind model plays a significant role in calculating availabilities from surface (e.g., SLF) data, and can differ substantially from availabilities based on measurements at the height of interest.

\section{B. Temperature vs. Wind Speed Comparison Between Pad 39 B and Tower 313}

A second example of meteorological tower data being used in engineering analyses is an application which is sensitive to particular combinations of wind speed and temperature. One such application is a purging operation which occurs on the Ares I launch vehicle as it is sitting on the pad. This operation is sensitive to relatively cold temperatures occurring near $122 \mathrm{~m}$. Although the Pad 39B tower is located closer to the pad itself than Tower 313, Tower 313 has measurements much closer to the heights of interest, though the simultaneous temperature and wind measurements would have to be taken from two different heights. For this reason, a comparison was performed between the two measurement sources to see if any significant differences in the probabilities of given wind speed and temperature combinations existed.

To perform this analysis, the joint probability of a particular wind speed and a temperature within the specified bin was examined. Temperatures were binned in $2.7^{\circ} \mathrm{C}$ increments from $-2.4^{\circ} \mathrm{C}$ to $11.4{ }^{\circ} \mathrm{C}$, but wind speeds were not binned. Rather, wind speed values (in $\mathrm{m} / \mathrm{s}$ ), which represented $0-45$ miles per hour ( $\mathrm{mph}$ ) at every $5 \mathrm{mph}$ mark (as requested by engineering customer), were examined. The number of reports where the wind speed equaled each particular value and the temperature fell within each specified bin were divided by the total number of valid, concurrent wind and temperature reports in each month. From Tower 313, wind speed at $120 \mathrm{~m}$ was examined with temperature at $150 \mathrm{~m}$. However, both variables were examined at $18.3 \mathrm{~m}$ from Pad 39B. Table 2 shows the results for the month of because it contained the most instances of those thresholds occurring simultaneously (i.e., January had the highest probabilities of occurrence).

Table 2. Probability of occurrence (\%) for specified temperature ranges and wind speed thresholds from a) Tower 313 and b) Pad 39B.

a) JANUARY

$\%$ Probability of Occurrence (Tower 313 )

\begin{tabular}{|c|c|c|c|c|c|c|c|c|c|c|}
\hline \multirow{3}{*}{$\begin{array}{l}\text { JANUARY } \\
\text { temp: } z=150 \mathrm{~m} \\
\text { Temp }\left({ }^{\circ} \mathrm{C}\right)\end{array}$} & \multirow{2}{*}{\multicolumn{10}{|c|}{ Wind: $z=120 \mathrm{~m} \quad$ Mean Wind Speed $(\mathrm{m} / \mathrm{s})$}} \\
\hline & & & & & & & & & & \\
\hline & 0.0 & 2.1 & 4.6 & 6.7 & 8.7 & 11.3 & 13.4 & 15.4 & 18.0 & 20.1 \\
\hline$-2.4-0.3$ & 0.000000 & 0.000000 & 0.000000 & 0.001238 & 0.017332 & 0.019808 & 0.030951 & 0.001238 & 0.000000 & 0.000000 \\
\hline $0.3-3.1$ & 0.000000 & 0.000000 & 0.000000 & 0.016094 & 0.107708 & 0.056949 & 0.013618 & 0.000000 & 0.000000 & 0.000000 \\
\hline $3.1-5.8$ & 0.000000 & 0.001238 & 0.044569 & 0.107708 & 0.278555 & 0.165895 & 0.030951 & 0.001238 & 0.000000 & 0.000000 \\
\hline $5.8-8.6$ & 0.000000 & 0.017332 & 0.103994 & 0.276079 & 0.368931 & \begin{tabular}{l|l}
0.186941 \\
\end{tabular} & 0.022284 & 0.001238 & 0.000000 & 0.000000 \\
\hline $8.6-11.4$ & 0.021046 & 0.139896 & \begin{tabular}{ll|}
0.240176 \\
\end{tabular} & 0.497685 & 0.649962 & 0.325600 & 0.121326 & 0.039617 & 0.000000 & 0.000000 \\
\hline
\end{tabular}

b)

\begin{tabular}{|c|c|c|c|c|c|c|c|c|c|c|}
\hline \multirow{3}{*}{\begin{tabular}{|l}
$\begin{array}{l}\text { JANUARY } \\
\text { temp: } z=18.3 \mathrm{~m}\end{array}$ \\
Temp $\left({ }^{\circ} \mathrm{C}\right)$
\end{tabular}} & \multirow{2}{*}{\multicolumn{4}{|c|}{ wind: $z=18.3 \mathrm{~m}$}} & \multirow{2}{*}{\multicolumn{6}{|c|}{ Mean Wind Speed (m/s) }} \\
\hline & & & & & & & & & & \\
\hline & 0.0 & 2.1 & 4.6 & 6.7 & 8.7 & 11.3 & 13.4 & 15.4 & 18.0 & 20.1 \\
\hline$-2.4-0.3$ & 0.000000 & 0.000000 & 0.015765 & 0.014332 & 0.022931 & 0.007166 & 0.000000 & 0.000000 & 0.000000 & 0.000000 \\
\hline $0.3-3.1$ & 0.002866 & 0.000000 & 0.187749 & 0.064494 & 0.025798 & 0.012899 & 0.000000 & 0.000000 & 0.000000 & 0.000000 \\
\hline $3.1-5.8$ & 0.000000 & 0.070227 & 0.322470 & 0.233611 & 0.123255 & 0.007166 & 0.000000 & 0.000000 & 0.000000 & 0.000000 \\
\hline $5.8-8.6$ & 0.000000 & 0.149053 & 0.576146 & 0.265142 & 0.139020 & 0.011466 & 0.000000 & 0.000000 & 0.000000 & 0.000000 \\
\hline $8.6-11.4$ & 0.010032 & 0.386964 & 0.884284 & 0.325336 & 0.143320 & 0.028664 & 0.001433 & 0.000000 & 0.000000 & 0.000000 \\
\hline
\end{tabular}


The results in Table 2 show a very low probability of encountering the given wind speed and temperature combinations from both sources though, depending on the engineering application of the results, these differences could be significant. The highest probability from both datasets is the probability of a $4.6 \mathrm{~m} / \mathrm{s}$ wind occurring with a temperature between $8.6^{\circ} \mathrm{C}$ and $11.4{ }^{\circ} \mathrm{C}$ from Pad 39B, which is $0.884 \%$. The probability of this same combination occurring from Tower 313 is $0.240 \%$, yielding a difference of $\sim 0.644 \%$. At first glance, and for some applications, differences at this probability level might be considered too low to have any impact on the engineering analysis or decision. However, as mentioned in Section I of this paper, EV44 is responsible for defining the extremes of the environment for engineering applications. Here, the word "extreme" usually refers to probabilities of occurrence (or, 'risks') lower than $1.0 \%$. Thus, if a particular wind speed and temperature combination is defined as the "extreme" environment, its probability should be small enough to tolerate the risk of it occurring. For example, if the customer determined that a $0.5 \%$ risk is the highest risk that a given application can tolerate, then the results for the combination described above for Pad 39B $(0.884 \%)$ would not meet the risk criteria, while the result for Tower $313(0.240 \%)$ would meet the risk criteria. When situations such as these arise, additional rationale has to be developed for choosing one data source over the other. If the application is near the pad at approximately $18.3 \mathrm{~m}$, then the results from Pad 39B would be favored. However, for applications at different heights, such as the purge analysis mentioned above, Tower 313 would be preferred.

\section{Temperature vs. Dewpoint Comparison Between SLF and Pad 39B}

Another concern for various groups within the $\mathrm{CxP}$ relates to how ground support equipment will handle various temperature and dewpoint combinations at locations such as KSC. Some of this equipment is used to create a benign environment for the vehicle while it is worked on and moved around various KSC facilities prior to launch. High temperatures with high dewpoints can create a very moist and unstable environment, causing ground support equipment to have to work harder to maintain a stable environment. The same holds true if the other extreme occurs - very low temperatures with very low dewpoints.

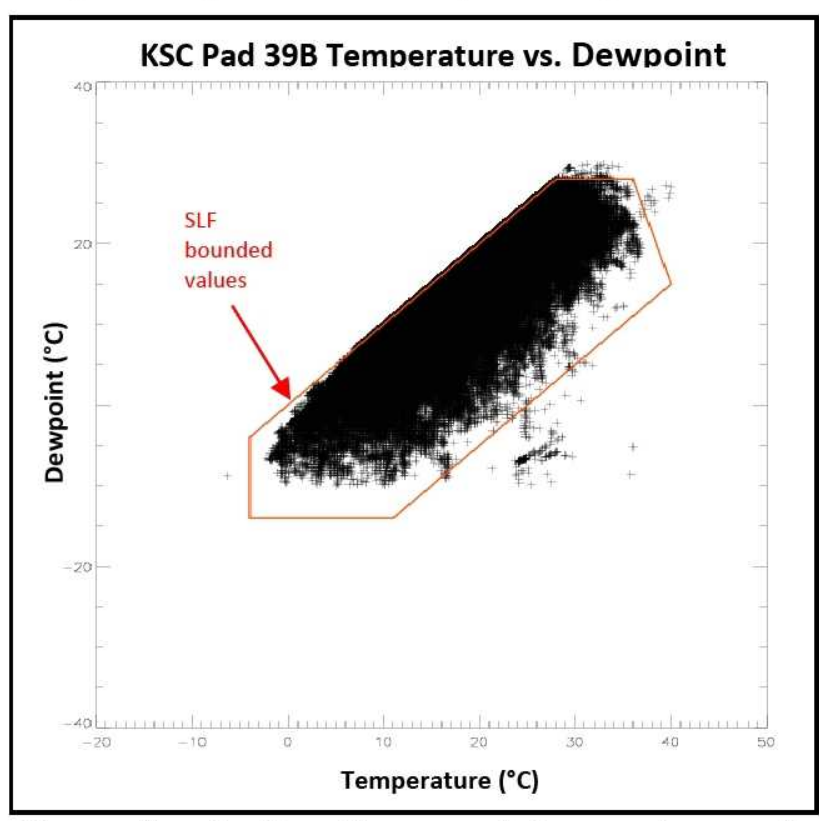

Figure 2. Scatter diagram of temperature and dewpoint from Pad 39B. Temperature and dewpoint are in ${ }^{\circ} \mathrm{C}$. A psychrometric plot of temperature and dewpoint which bounds SLF temperature and dewpoint combinations is overlaid in red.
Differences in temperature and dewpoint combinations exist between Pad 39B and the SLF, but the extremes of the SLF database seem to envelope the Pad 39B database. Pad 39B collects data near the shoreline, only a half mile inland. The SLF tower is further inland and records values closer to the ground. Therefore, some differences in temperatures and dewpoints between the two towers are expected. The scatter plot in Fig. 2 shows the temperature vs. dewpoint values for all the data records in the Pad 39B database for the 1995-2007 POR. The red boundaries capture the SLF temperature vs. dewpoint limits - a psychrometric chart created for inclusion within the DSNE. Nearly all the Pad 39B temperature and dewpoint data fall within the SLF boundaries. Some of the Pad 39B data points that fall outside the SLF boundaries may be suspect data and, for a more detailed analysis, would be further examined to better understand the QC process and to look at the validity of those values. Since the majority of the points fall well within the SLF boundaries, it appears that the towers recorded similar data. However, the spatial difference between the towers is also evident. Closer to the shore, the air does not seem to get as cold and as dry as the air at the SLF, which could be because the winds coming off the water keep air warm and moist near the shoreline while cooler,

drier air exists further inland at the SLF. Regardless of the differences which exist between individual observations within the two datasets, Fig. 2 shows that the extreme temperature and dewpoint observations are enveloped by the SLF database. Customers performing analyses sensitive to low temperature and low dewpoint combinations might consider where the application is being performed relative to the location of the towers and the measurement height as cooler and drier air tends to exist at the SLF more often than at Pad 39B. 


\section{Conclusions}

Defining the environments includes deciding which database provides the meteorological information which most directly applies to the given analysis. Many different measurement sources exist at KSC, but meteorological towers - such as the three towers discussed in this paper - are preferred for near-surface applications. The analyses presented herein show example comparisons between meteorological variables measured at different towers at KSC. These comparisons were performed to show that using a dataset from a tower which is not in the direct vicinity of an engineering application can misrepresent the environments in which the engineering community is trying to design or work toward. Three examples were presented - with the first showing peak wind speed availabilities calculated using the SLF database with the NEDD model and from measurements from Tower 313 near the $90 \mathrm{~m}$ height of interest. Availabilities at $90 \mathrm{~m}$ can vary greatly between using the Tower 313 database and the SLF. Although the SLF has a longer POR, it takes wind measurements at $10 \mathrm{~m}$ and one must use a model to derive an associated wind speed at $90 \mathrm{~m}$ against which to test. The NEDD model envelopes the peak winds at given sigma levels, so the associated wind speed at $90 \mathrm{~m}$ depends on the chosen sigma level. The comparison shows that using the SLF data with the NEDD model does not replace using measured data at the height of interest. The second tower comparison looked at joint probabilities of particular temperature and wind speed combinations that were derived from Tower 313 and Pad 39B. Although those probabilities are considered small by most standards, potentially significant differences exist at "extreme" probability levels. These differences could impact a particular engineering application depending on the risk level in which the customer can accept. The final comparison showed temperature and dewpoint combinations compared between the SLF and Pad 39B. Although Pad 39B observations were enveloped by the SLF database, the engineering community could be concerned that using one database over the other may not lead to adequate protection from extreme low temperature and low dewpoint combinations.

These comparisons show examples of database attributes of which EV44 considers before deciding on a particular database to apply to NASA engineering analyses at KSC. The proximity of towers at KSC to the location of a particular application affects the environmental input to that application. Therefore, EV44 examines characteristics of each tower prior to use. The variety of instrumentation at KSC - of which the towers are only one type of source - allows a wide range of meteorological data to be examined for various engineering applications so that EV44 can supply the most appropriate and relevant information to the engineering community for implementation into space vehicle design.

\section{Acknowledgments}

Contributions to this study were provided by colleagues in the Natural Environments Branch/EV44, including Frank Leahy (NASA), who provided information regarding the use of the peak wind model, and Dr. Stanley Adelfang (Stanley Associates) who provided useful discussions about analytical and statistical methodologies.

\section{References}

${ }^{1}$ NASA CxP-70023, "Constellation Program Design Specification for Natural Environments, Revision A, Change 001," Marshall Space Flight Center, 7 November 2008.

${ }^{2}$ NASA CxP-70044, "Constellation Program Natural Environment Definition for Design, Revision A," Marshall Space Flight Center, 24 September 2008.

${ }^{3}$ Decker, R. K, "Kennedy Space Center Launch Complex 39 Meteorological Databases", Presentation to the Space Shuttle Program Natural Environments Panel. 28 February 2008.

${ }^{4}$ Barbré, R. E., "Quality Control Algorithms Used for the KSC Tower 313 Database", Technical White Paper ESTSG-FY081481, Jacobs ESTS Group, Huntsville, AL, 2008.

${ }^{5}$ Barbré, R. E., "Wind Analyses from Kennedy Space Center", Technical White Paper ESTSG-FY08-01479, Jacobs ESTS Group, Huntsville, AL, 2008. 


\title{
Applications of Meteorological Tower Data at Kennedy Space Center
}

\author{
Karen M. Altino/NASA \\ \&. \\ Robert E. Barbré, Jr./Jacobs ESTS Group
}

NASA MSFC Natural Environments Branch/EV44 


\section{Outline}

- Introduction

- Kennedy Space Center (KSC) Meteorological Towers

- Examples of Database Comparisons

- Summary 


\section{MSFC Natural Environments Branch}

- Natural environments affect each and every mission phase of spaceflight.

- Pre-launch operations and hardware

- Launch and ascent operations

- In-orbit space operations

- Earth landing and recovery operations

- The Natural Environments Branch/EV44, located at NASA/MSFC, provides expertise in understanding natural environment effects on the various systems of space vehicles.

- Natural environments form fundamental constraints to a vehicle's design and operability, constraints that design engineers must address in terms of robust design, operational mitigation, and mission risk.

- The Terrestrial Environments Team of EV44 is responsible for providing its NASA customers with meteorological data using various climatological data sources including balloons, surface stations, aircraft, hindcast models, and meteorological towers. 


\section{Kennedy Space Center Meteorological Data Sources}

- Multitude of data available at KSC recorded by instrumentation such as meteorological towers, lightning detection systems and electric field mills, profilers, and weather balloons.

- For near-surface observations, EV44 utilizes the towers because they record data at regular, frequent intervals and data is continuously archived.

- EV44 considers the tower locations, measurements recorded, and the observation height to make sure the most applicable information is utilized for each engineering analysis.

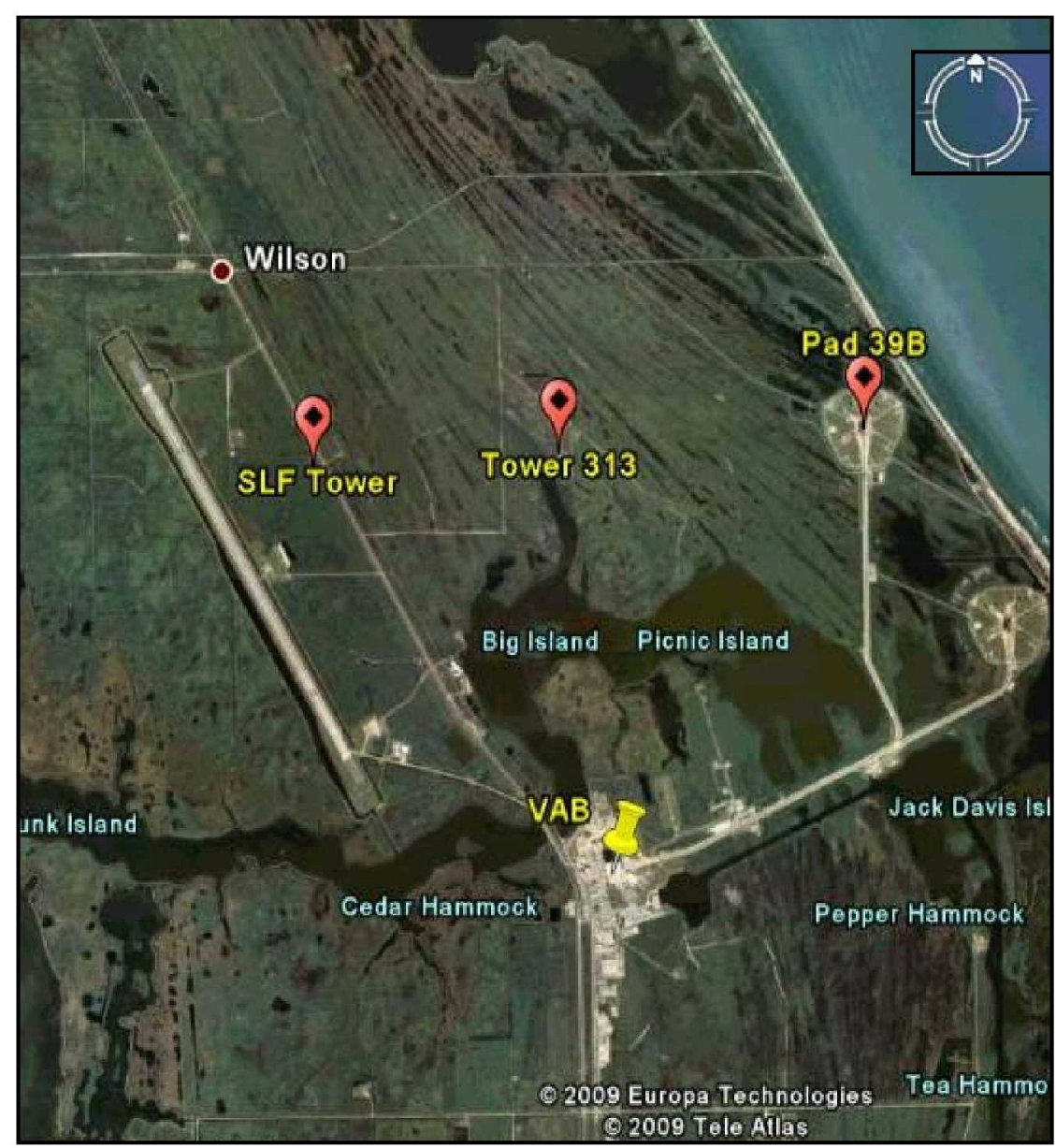

Image using Google Earth global mapping 


\section{KSC METEOROLOGICAL TOWERS}




\section{Shuttle Landing Facility (SLF) Tower}

- Located approximately $6.4 \mathrm{~km}$ inland.

- Period of Record (POR): 1978 - Present

- Meteorological measurements taken at $10 \mathrm{~m}$ height.

- Database contains hourly records.

- Measures values for variables such as temperature, dewpoint, wind speed, and wind direction.

- For most variables, the hourly recorded value is the mean value over the last five minutes of the previous hour.

- Peak wind speed values are recorded as the highest 1-second gust over that five-minute period.

- Data is quality-controlled (qc'd) and archived through NOAA's National Climatic Data Center (NCDC) / Air Force Combat Climatology Center (AFCCC) located in Asheville, North Carolina. 


\section{Pad 39B Tower}

- Located approximately $0.8 \mathbf{~ k m}$ inland.

- POR: 1995 - 2007

- Meteorological measurements taken at $18.3 \mathrm{~m}$ height.

- Database contains 5-minute records.

- Measurements recorded at two individual towers near pad - one on the northwest and one on the southeast side.

- Each 5-minute record contains 5-minute averages of temperature, dewpoint, relative humidity, wind speed, and wind direction - including the maximum 1-second peak wind speed during the reporting period.

- Temperature and dewpoint are recorded to the nearest $0.1^{\circ} \mathrm{C}$, with the dewpoint calculated in the data post-processing.

- Relative humidity is reported to the nearest whole \%.

- Wind speed is measured in integer knots, but is converted to $\mathrm{m} / \mathrm{s}$.

- Data is recorded at KSC and given to EV44, but is not qc'd. Data has to be qc'd internally and a single database is generated from the measurements taken at the two towers. 
- Located approximately 3.9 km inland.

- POR: 1995 - 2007

- Meteorological measurements taken at multiple heights on tower by two sensors - one situated on northeast side and one on southwest side.

- Measurements recorded at heights of approximately $2 \mathrm{~m}, 4 \mathrm{~m}, 16 \mathrm{~m}, 49 \mathrm{~m}$, $62 \mathrm{~m}, 90 \mathrm{~m}, 120 \mathrm{~m}$, and up to $150 \mathrm{~m}$.

- Wind speed and direction measured at all heights except at $2 \mathrm{~m}$.

- Temperature, dewpoint, and relative humidity are only recorded at four heights $-2 \mathrm{~m}, 16 \mathrm{~m}, 62 \mathrm{~m}$, and $150 \mathrm{~m}$.

- Database contains 5-minute records.

- Characteristics of each variable are analogous to the Pad 39B database.

- Data is recorded at KSC and given to EV44, but is not qc'd. Data has to be qc'd internally and a single database is generated from the measurements taken at the two sensors. 


\section{EXAMPLES OF DATABASE COMPARISONS}




\section{Peak Wind Speed Comparison Between Tower 313 and SLF}

- Examined peak wind speed differences between SLF and Tower 313 for an engineering analysis request regarding winds at $90 \mathrm{~m}$ height.

- Calculated availabilities, or cumulative probabilities of not occurring, for peak wind speeds at $10 \mathrm{~m}$ from SLF.

- The $10 \mathrm{~m}$ peak wind speed thresholds were extrapolated up to $89.9 \mathrm{~m}$ using a peak wind model for KSC developed at MSFC. Tower 313 contains observations at $89.9 \mathrm{~m}$.

- Model requires a standard deviation input, $n$, which envelopes peak wind profiles corresponding to a given wind speed at the reference altitude to a specified risk level.

- Calculated corresponding availabilities of extrapolated $89.9 \mathrm{~m}$ peak wind speeds at $89.9 \mathrm{~m}$ from Tower 313 using $n=0,1,2$.

- Subtracted Tower 313 availabilities from SLF availabilities as a function of month and $10 \mathrm{~m}$ wind speed.

- Analysis tests validity of extrapolating data from a lower altitude to a higher altitude using a model. 


\section{Peak Wind Speed Comparison Between Tower 313 and SLF for $n=0$}

- Using SLF will result > 10\% greater availabilities than Tower 313 for low $10 \mathrm{~m}$ peak wind speeds from August - May.

- Tower 313 has greater availabilities from March - August at moderate to high $\mathbf{1 0} \mathrm{m}$ peak wind speeds.

- Using the model with $\boldsymbol{n}=\mathbf{0}$ may or may not yield similar availabilities to the availabilities based on peak wind speeds near the altitude of interest, depending on the month and peak wind speed chosen.

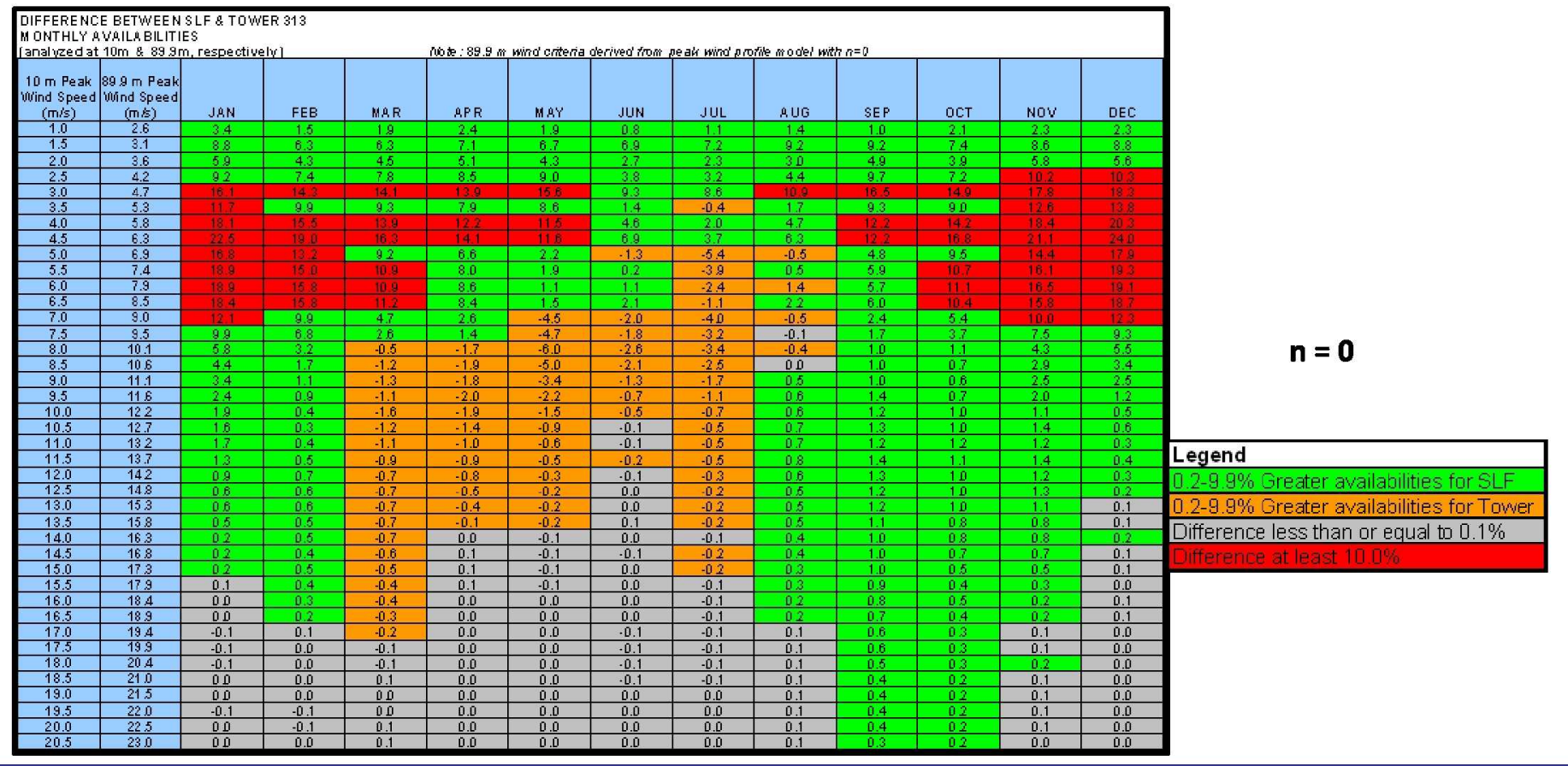




\section{Peak Wind Speed Comparison Between Tower 313 and SLF for $n=1$}

- The $89.9 \mathrm{~m}$ peak wind speed corresponding to the given $10 \mathrm{~m}$ peak wind speed increases compared to the $n=0$ case.

- Implies greater availabilities from Tower 313.

- Availability differences have essentially reversed in sign compared to the $n=0$ case.

- Greater availabilities exist for Tower $\mathbf{3 1 3}$ for the majority of the wind speeds and months, with $>10 \%$ differences existing from March October.

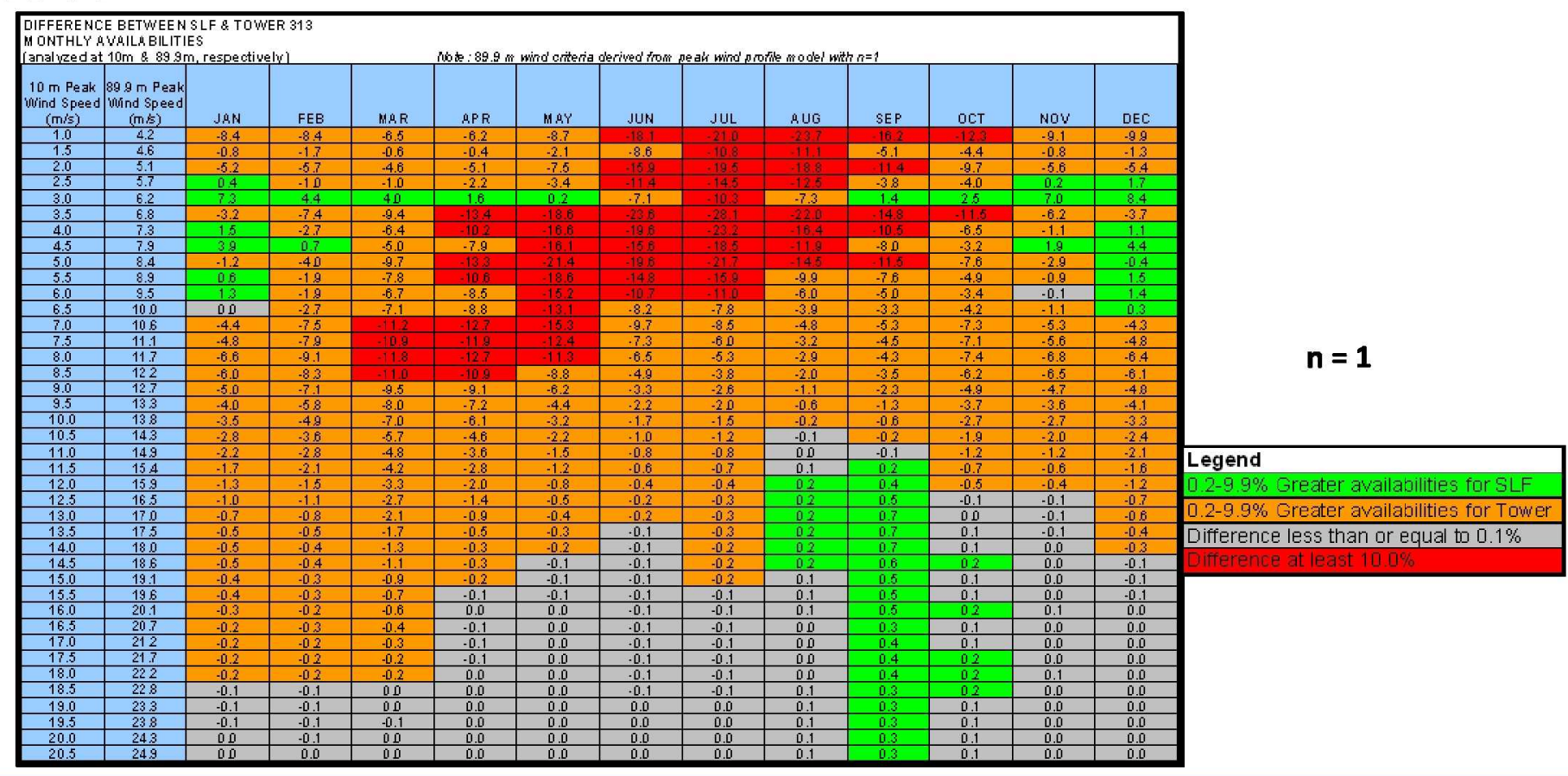




\section{Peak Wind Speed Comparison Between Tower 313 and SLF for $n=2$}

- The $89.9 \mathrm{~m}$ peak wind speed corresponding to the given $10 \mathrm{~m}$ peak wind speed increases compared to the $n=1$ case.

- Implies an increase in Tower 313 availabilities from the $n=1$ case.

- Tower 313 contains greater availabilities for nearly all months and peak wind speed combinations, with $>10 \%$ difference for lower $10 \mathrm{~m}$ peak wind speeds.

- These tests show that availabilities derived from extrapolating $10 \mathrm{~m}$ data to $89.9 \mathrm{~m}$ can differ substantially from those based on measurements at the altitude of interest.

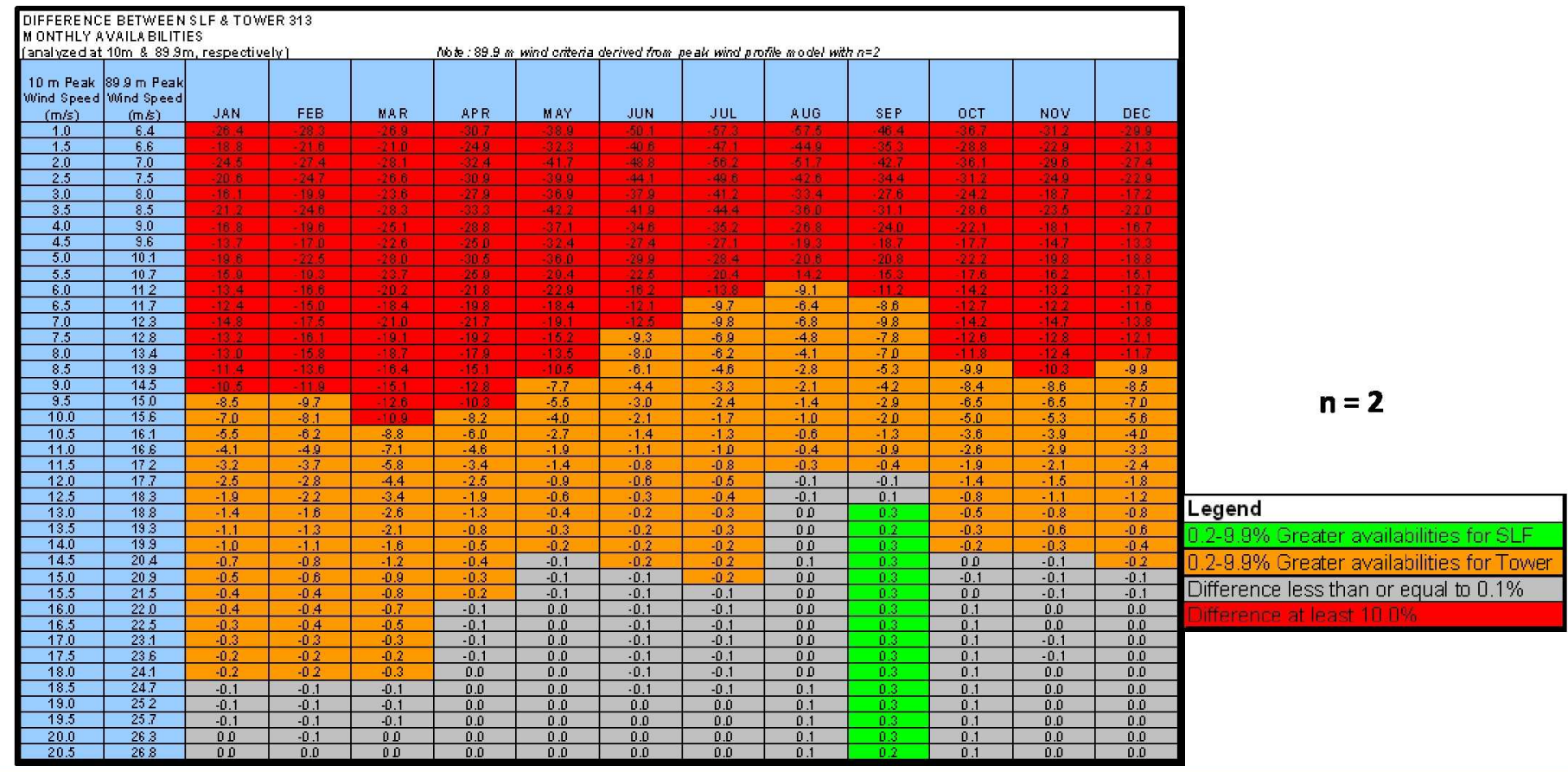




\section{Wind Speed vs. Temperature Comparison Between Tower 313 and Pad 39B}

- EV44 was presented with an engineering application in which cold temperatures combined with varying mean wind speeds (at a height of approximately $122 \mathrm{~m}$ ) influence the thermal effects on a piece of hardware while on the launch pad.

- Pad 39B is closer, but Tower 313 contains measurements at the closest relevant height(s) - wind speed @ 120 m, temperature @ 150 m.

- The month of January returned the highest probability of occurrence.

- Even though occurrence probabilities are small at either location, the sensitivity of the equipment means even a small chance of occurrence could be critical.

- Because of critical height sensitivity, the recommendation would be to use Tower 313 in this case in spite of its location further away.

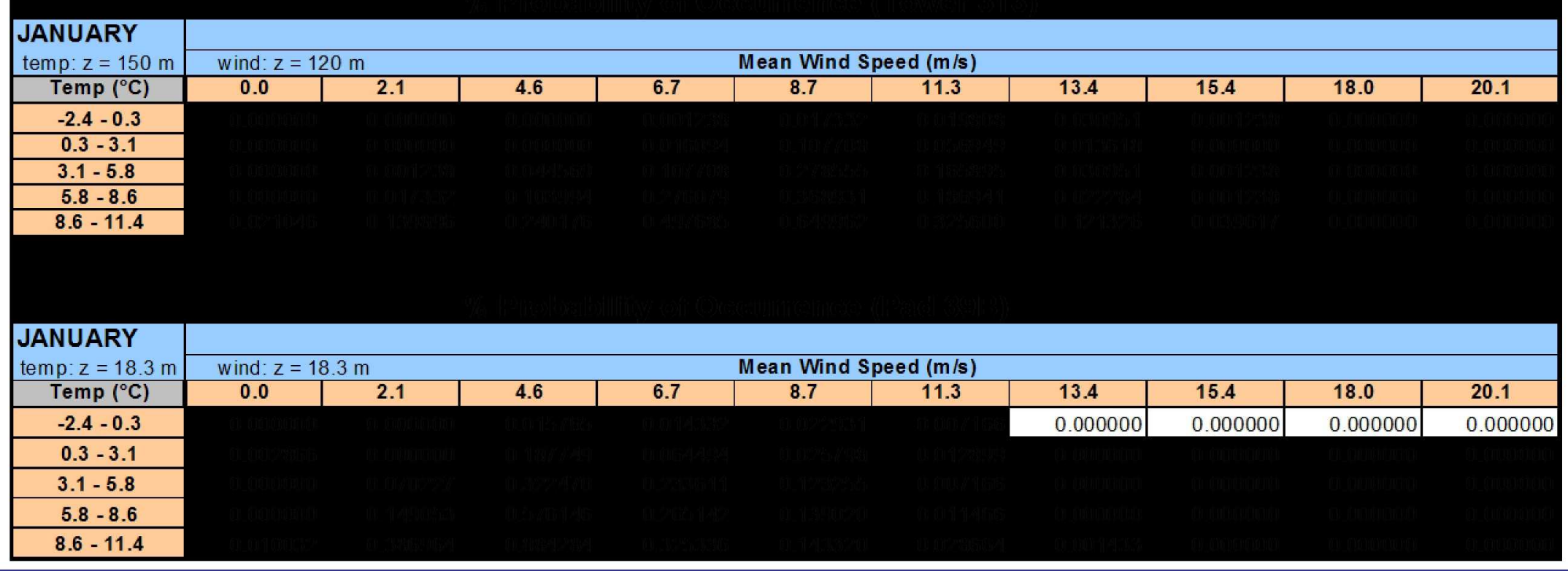




\section{Temperature vs. Dewpoint Comparison Between Pad 39B and SLF}

- Examined temperature vs. dewpoint for engineering analysis related to ground support equipment use near the launch pads.

- For a previous study, EV44 had created a psychrometric chart of SLF environments.

- The red boundaries capture the SLF temperature vs. dewpoint limits.

- Nearly all the Pad 39B temperature and dewpoint data fell within those boundaries.

- Although the towers recorded similar data, the spatial difference between the towers is also evident.

- Air further inland at the SLF can be cooler and drier - not affected by warmth and moisture coming off of

KSC Pad 39B Temperature vs. Dewpoint @ 18.3 m

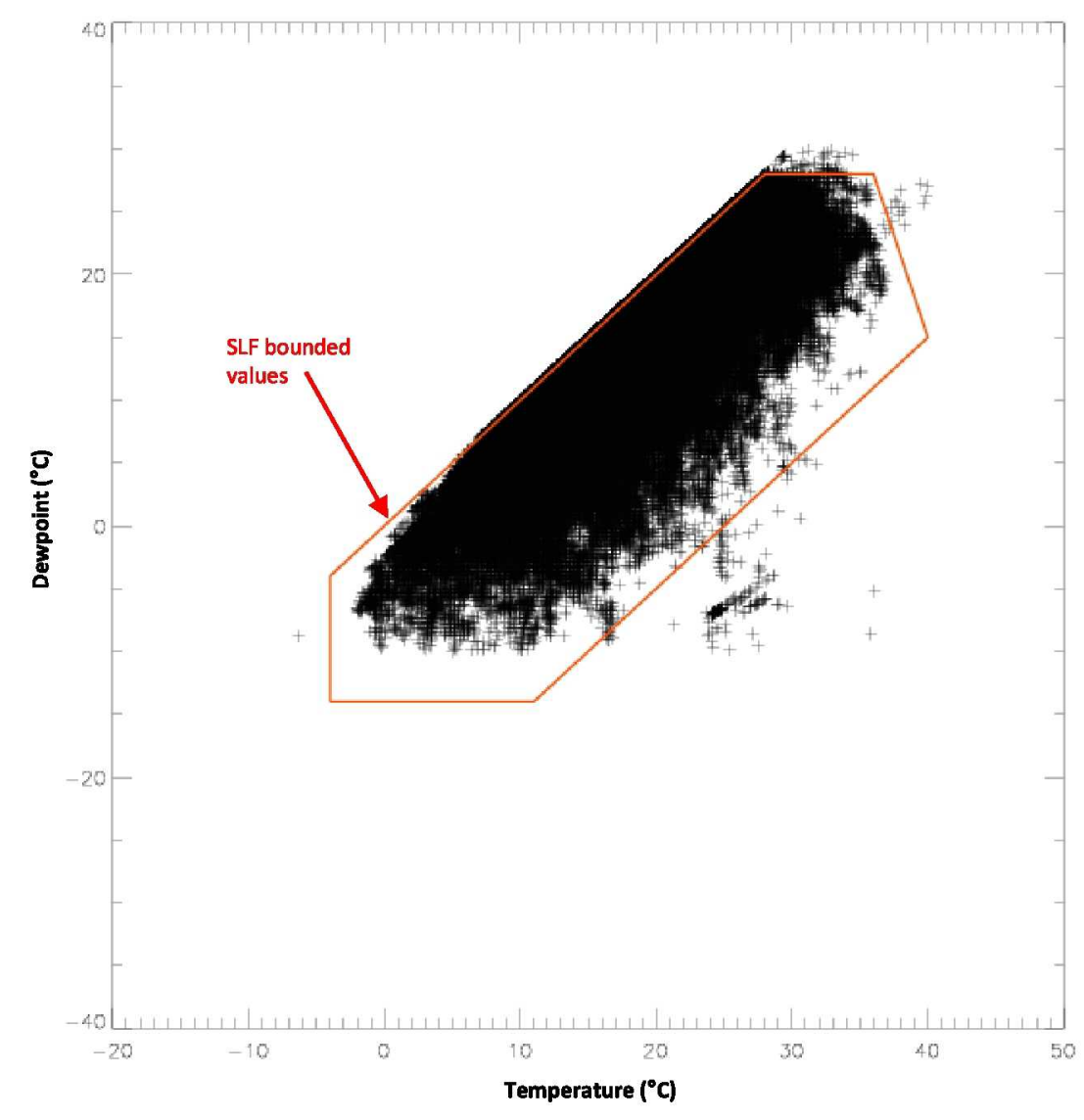
ocean. 
- The variety of instrumentation at KSC - of which the towers are only one type of source - allows a wide range of meteorological data to be examined for various engineering applications.

- New lightning protection system currently being installed at the launch pads in anticipation of the new Constellation vehicles will allow multiheight meteorological measurements at each pad.

- The comparisons on the previous slides show that using a dataset from a tower which is not in the direct vicinity of an engineering application can misrepresent the environments in which the engineering community is trying to design or work toward.

- Spatial variance and observation height differences between the instrumentation means that each tower is being influenced by varying meteorological effects.

- Storms, winds, sea breeze, and diurnal effects.

- For the Natural Environments Branch, defining the environments includes deciding which database provides the meteorological information which most directly applies to the given engineering analysis. 